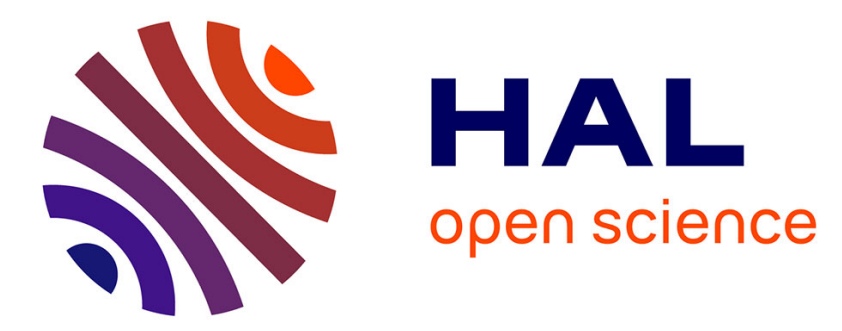

\title{
Theoretical study of gas heated in a porous material subjected to a concentrated solar radiation
}

\author{
G. Olalde, J.L. Peube, M. Daguenet
}

\section{To cite this version:}

G. Olalde, J.L. Peube, M. Daguenet. Theoretical study of gas heated in a porous material subjected to a concentrated solar radiation. Revue de Physique Appliquée, 1980, 15 (3), pp.423-426. 10.1051/rphysap:01980001503042300 . jpa-00244748

\section{HAL Id: jpa-00244748 https://hal.science/jpa-00244748}

Submitted on 1 Jan 1980

HAL is a multi-disciplinary open access archive for the deposit and dissemination of scientific research documents, whether they are published or not. The documents may come from teaching and research institutions in France or abroad, or from public or private research centers.
L'archive ouverte pluridisciplinaire HAL, est destinée au dépôt et à la diffusion de documents scientifiques de niveau recherche, publiés ou non, émanant des établissements d'enseignement et de recherche français ou étrangers, des laboratoires publics ou privés. 


\title{
Theoretical study of gas heated in a porous material subjected to a concentrated solar radiation $(*)$
}

\author{
G. Olalde $\left({ }^{1}\right)$, J. L. Peube $\left({ }^{1}\right)$ and M. Daguenet $\left({ }^{2}\right)$ \\ (1) Laboratoire d'Energétique Solaire, BP 5, Odeillo, 66120 Font Romeu, France \\ $\left({ }^{2}\right)$ Laboratoire de Thermodynamique et Energétique, Université de Perpignan, 66025 Cedex, France
}

(Reçu le 26 juillet 1979, révisé le 23 novembre 1979, accepté le 26 novembre 1979)

\begin{abstract}
Résumé. - Les auteurs calculent analytiquement et numériquement la distribution des températures dans le solide (matériau poreux) et le fluide (gaz) en fonction des paramètres du système. Un réacteur expérimental a été conçu et installé au four solaire de $6,5 \mathrm{~kW}$ du Laboratoire d'Energétique Solaire à Odeillo (France). Différentes expériences ont été réalisées et ont permis de tester la validité du modèle théorique.

Abstract. - The authors calculate analytically and numerically temperature distribution in the solid (porous material) and the fluid (gas) from a system of adimensional equations composed of one differential equation of order 4 and another one of order 2 with constant coefficient. An experimental reactor was constructed for the verification of the model; it was designed to be used with $6.5 \mathrm{~kW}$ solar furnace of Solar Energy Laboratory in Odeillo (France).
\end{abstract}

\section{Nomenclature}

$A=$ surface area for theoretical transfers per unit volumen of porous material $(1-\xi) / \tau$;

$A i, A j, a j, B_{1}, b_{1}=$ constants ;

$C_{\mathrm{p}}=$ gas specific heat;

$D p=$ particle diameter ;

$h=$ heat transfer coefficient;

$L=$ porous material length;

$L^{+}=$dimensionless porous material length $L^{+}=L / D p$

$M i, M j, m j=$ constants ;

$N u=$ Nusselt dimensionless group ;

$\operatorname{Pr}=$ Prandtl dimensionless group;

$R e=$ Reynolds dimensionless group based on packing size, $D p$;

$T=$ solid temperature;

$T^{+}=$solid dimensionless temperature;

$X=$ coordinate, axial distance through the porous material ;

$X^{+}=$dimensionless axial distance through the porous material $X^{+}=X / D p$

$v=$ fluid average velocity in the axial direction;

$V o=$ fluid velocity in the empty column, $V o=\xi v$.

$\left.{ }^{*}\right)$ Presented at the ISES International Congress Atlanta, Georgia May 28, 1979.

\section{Greek symbols}

$\xi=$ porosity

$\tau=$ characteristic lenght of the form of the particles $\tau=D p / 6$ for spheres ;

$\rho=$ gas density

$\mu=$ viscosity

$\theta=$ fluid temperature

$\theta^{+}=$dimensionless fluid temperature;

$\lambda_{\mathrm{F}}=$ gas thermal conductivity;

$\lambda_{\mathrm{S}}^{*}=$ solid apparent thermal conductivity due to radiation, to solid contacts and to the neighbourhood of these contacts in which the fluid is considered at rest.

\section{Subscripts}

$\mathrm{a}=$ ambient

$\mathrm{o}=$ side of the porous material exposed to the solar radiation.

These quantities may be expressed in any set consistent units.

1. Introduction. - Heating of gases at high temperature can be useful for chemistry (solid-gas reactions), physics (drying, distillation), thermodynamics (thermo-helio-electric power plants), etc. The gas being in general a poor absorber of solar 
radiation one way is to make them passing through a divided medium which presents a large contact area. Porous material find a central place as a processing tool in a wide variety of operations due to their large surface area and good fluid mixing properties.

Any evaluation and prediction of heat transfer in a porous media must account for the two-phase nature of the system by examining the contribution of the three basic heat transfer modes; conduction, convection and radiation. When the gas flows through the porous material the three modes contribute to the heat transfer in the form of various mechanisms which interact by a number of series an parallel paths, while for a stagnant gas, conduction and radiation are the significant modes [1-4].

2. Theory. - In the treatment of the problem, the following hypothesis are made :

a) the gas is transparent to the radiation;

b) the porous material composed of equal-sized spheres may be characterized by a constant bulk porosity;

c) steady state and one-dimensional conditions are supposed ;

d) the physical properties of the fluid and solide are constant;

$e$ ) the incident radiative flux is uniform and irradiates the upper surface of the porous material.

The heat balance equations under these conditions for the gas and solid are :

$$
\begin{gathered}
C_{\mathrm{p}} \rho v \frac{\mathrm{d} \theta}{\mathrm{d} X}=\frac{1-\xi}{\xi} \frac{h}{\tau}(T-0)+\lambda_{\mathrm{F}} \frac{\mathrm{d}^{2} \theta}{\mathrm{d} X^{2}} \\
\lambda_{\mathrm{S}}^{*} \frac{\mathrm{d}^{2} T}{\mathrm{~d} X^{2}}=\frac{h}{\tau}(T-0) .
\end{gathered}
$$

The heat transfer coefficient $h$ between the fluid and the solid depends in this case on the fluid velocity $v$, according to an unknown relation, function of all the system characteristics.

Consenquently it was necessary to use are empirical relation in the numerical calculation to find the temperature profiles [5].

$$
\begin{aligned}
& \text { For } 0<\left(\frac{1-\xi}{\xi}\right) R e<600 \\
& \qquad N u=2.62 \times 10^{-4}\left(\frac{1-\xi}{\xi^{3}}\right)^{1.6} R e^{1.6} \\
& \text { For }\left(\frac{1-\xi}{\xi}\right) \operatorname{Re}>600 \\
& N u=6.6 \times 10^{-2}\left(\frac{1-\xi}{\xi^{3}}\right)^{0.75} R e^{0.75}
\end{aligned}
$$

with

$$
R e=\frac{\rho V o D p}{\mu}
$$

The case of the gas circulating in the direction of the heat flow is called co-current case. The alternate case of the gas circulating in the opposite direction is called counter current case.

\section{Co-current case}

It is supposed that

$$
\begin{aligned}
T^{+} & =\frac{T-\theta_{0}}{T o-\theta_{0}} ; \\
0^{+} & =\frac{\theta-\theta_{0}}{T o-\theta_{0}} ; \\
X^{+} & =\frac{X}{D p} .
\end{aligned}
$$

The differential systems of the equations (1) and (2) becomes

$$
\begin{gathered}
\frac{\mathrm{d}^{4} T^{+}}{\mathrm{d} X^{+4}}-\frac{P r-R e}{\xi} \frac{\mathrm{d}^{3} T^{+}}{\mathrm{d} X^{+3}}-6 N u\left(\frac{1-\xi}{\xi}+\frac{\lambda_{\mathrm{F}}}{\lambda_{\mathrm{S}}^{*}}\right) \frac{\mathrm{d}^{2} T^{+}}{\mathrm{d} X^{+2}}+ \\
+6 \frac{\lambda_{\mathrm{F}}}{\lambda_{\mathrm{S}}^{*} \xi} \operatorname{RePrNu} \frac{\mathrm{d} T^{+}}{\mathrm{d} X^{+}}=0 \\
\theta^{+}=T^{+}-\frac{\lambda_{\mathrm{S}}^{*}}{6 N u \lambda_{\mathrm{F}}} \frac{\mathrm{d}^{2} T^{+}}{\mathrm{d} X^{+2}}
\end{gathered}
$$

with the boundary conditions

$$
\begin{aligned}
& X^{+}=0 \quad \theta^{+}=0 \quad T^{+}=1 \\
& X^{+}=\frac{L}{D p}=L^{+} \quad \operatorname{grad} \theta^{+}=\operatorname{grad} T^{+}=0
\end{aligned}
$$

the solution can be written [6]

$$
\begin{aligned}
& T^{+}=A i+\sum_{j=1}^{3} A j \mathrm{e}^{P j X^{+}} \\
& \theta^{+}=A i+\sum_{j=1}^{3} \text { ajAj } \mathrm{e}^{P j X^{+}} .
\end{aligned}
$$

The roots, $P j$, and the constants $A i, A j, a j$, are determined using the Bairstow's method [6].

The limit case when $L^{+} \rightarrow \infty$ can be directly studied by taking

$$
\begin{aligned}
T^{+} & =\frac{T-T_{\infty}}{T_{\infty}} \\
\theta^{+} & =\frac{\theta-\theta_{\infty}}{\theta_{\infty}}
\end{aligned}
$$

with the boundary conditions

$$
X^{+} \rightarrow \infty \quad \theta_{\infty}=T_{\infty}=\text { constant }
$$

the solution beeing :

$$
\begin{aligned}
& T^{+}=B_{1} \mathrm{e}^{P X^{+}} \\
& \theta^{+}=B_{1} b_{1} \mathrm{e}^{P X^{+}} .
\end{aligned}
$$




\section{Counter-current case}

It us convenient to take

$$
\begin{aligned}
T^{+} & =\frac{T-T o}{\theta_{\mathrm{L}}-T o} \\
\theta^{+} & =\frac{\theta-T o}{\theta_{\mathrm{L}}-T o} .
\end{aligned}
$$

The differential equations systems (1) and (2) becomes

$$
\begin{gathered}
\frac{\mathrm{d}^{4} T^{+}}{\mathrm{d} X^{+4}}+\frac{\operatorname{Pr} R e}{\xi} \frac{\mathrm{d}^{3} T^{+}}{\mathrm{d} X^{+3}}-6 N u\left(\frac{1-\xi}{\xi}+\frac{\lambda_{\mathrm{F}}}{\lambda_{\mathrm{S}}^{*}}\right) \frac{\mathrm{d}^{2} T^{+}}{\mathrm{d} X^{+2}}- \\
-6 \frac{\lambda_{\mathrm{F}}}{\lambda_{\mathrm{S}}^{*}} \frac{\operatorname{RePrNu}}{\xi} \frac{\mathrm{d} T^{+}}{\mathrm{d} X^{+}}=0 \\
\theta^{+}=T^{+}-\frac{\lambda_{\mathrm{S}}^{*}}{6 \lambda_{\mathrm{F}} N u} \frac{\mathrm{d}^{2} T^{+}}{\mathrm{d} X^{+2}}
\end{gathered}
$$

with the boundary conditions

$$
\begin{aligned}
& X^{+}=0 \quad T^{+}=0 \quad \operatorname{grad} \theta^{+}=0 \\
& X^{+}=L^{+} \quad \operatorname{grad} T^{+}=0 \quad \theta^{+}=1
\end{aligned}
$$

the solution can be written

$$
\begin{aligned}
& T^{+}=M i+\sum_{j=1}^{3} M j \mathrm{e}^{B j X^{+}} \\
& \theta^{+}=M i+\sum_{j=1}^{3} m j M j \mathrm{e}^{B j X^{+}}
\end{aligned}
$$

the roots, $B j$ and the constants $M i, M j, m j$ are determined using the Bairstow's method [6].

3. Experimental system. - A schematic drawing of the experimental arrangement is shown in figure 1 . It is composed of :

- a metallic cylindrical support;

- a quartz tube containing the porous material;

- the porous material surrounded with mineral

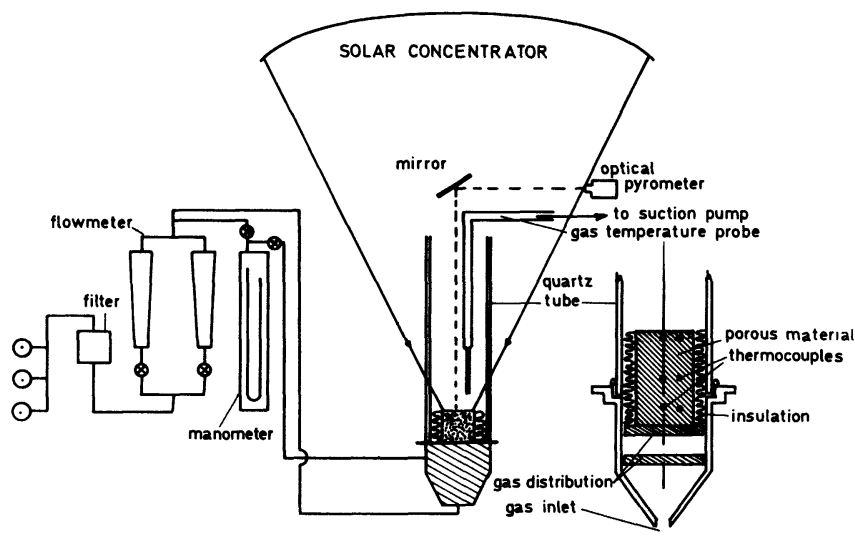

Fig. 1. - Schéma expérimental. Cas contre-courant.

[Schematic diagram of experimental unit. Counter-current case.] wool for lateral insulation to reduce radial heat transfer ;

- a set of chromel-alumel thermocouples located at different levels along the central axis of the bed and a second set along the periphery of the porous material ;

- a suction pyrometer realized with a Pt-PtRh $10 \%$ thermocouple and two $\mathrm{Al}_{2} \mathrm{O}_{3}$ radiation shields for the outlet air temperature measurement in counter current conditions ;

- flowmeters and differential manometer.

Filtered air is circulated through the porous material and released directly in the atmosphere; uniform velocity profiles within the bed beeing obtained by using a screen and packing of ceramic beads at the air inlet.

4. Results. - A first set of experiments with steady-state conditions were carried out on a cylindrical porous material of $\mathrm{SiC}$ of dimension $70 \mathrm{~mm}$, O.D. and $75 \mathrm{~mm}$ lenght. The mean porosity was $\xi=0.4$. Axial temperature profiles for two counter-current flow rates are shown in figure 2. Since the thermocouple are immersed in the porous material they indicate an average temperature which is neither that of the solid nor that of the gas.

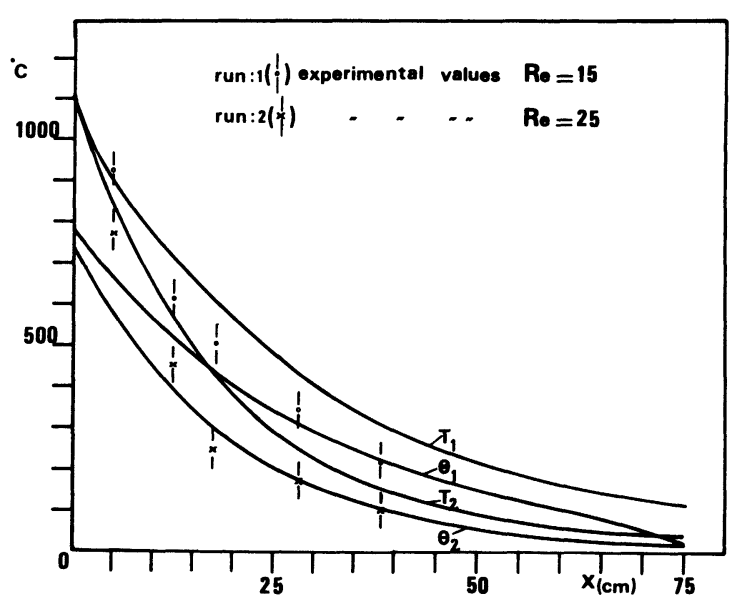

Fig. 2. - Profils des températures du solide (SiC) et du gaz (air) pour différentes valeurs de Reynolds $(L=75 \mathrm{~mm}, \xi=0,4)$ traits continus, valeurs théoriques. Cas contre-courant.

[Solid (SiC) and gas (air) temperatures profiles for gas flow runs (parameter refers to the Reynolds number values) solid line theoretical values. Counter-current case.]

Figures 3, 4 and 5 shown some theoretical values for air heated in counter-current flow in a porous material consisting of spheres of diameter $D p=3 \mathrm{~mm}$ and average porosity $\xi=0.4$. Figure 3 shown the profils of $T^{+}$and $\theta^{+}$as functions of $X^{+}$for a finite material $\left(L^{+}=10\right)$ and three different values of Reynolds number shown $\left(\lambda_{\mathrm{F}} / \lambda_{\mathrm{S}}^{*}\right.$ given), figure 4 showns for a given Reynolds number $(R e=20)$ and two different values of $\lambda_{\mathrm{F}} / \lambda_{\mathrm{S}}^{*}$ shown the profiles $T^{+}$ and $\theta^{+}$as function of $X^{+}$for a finite material $\left(L^{+}=10\right)$. 


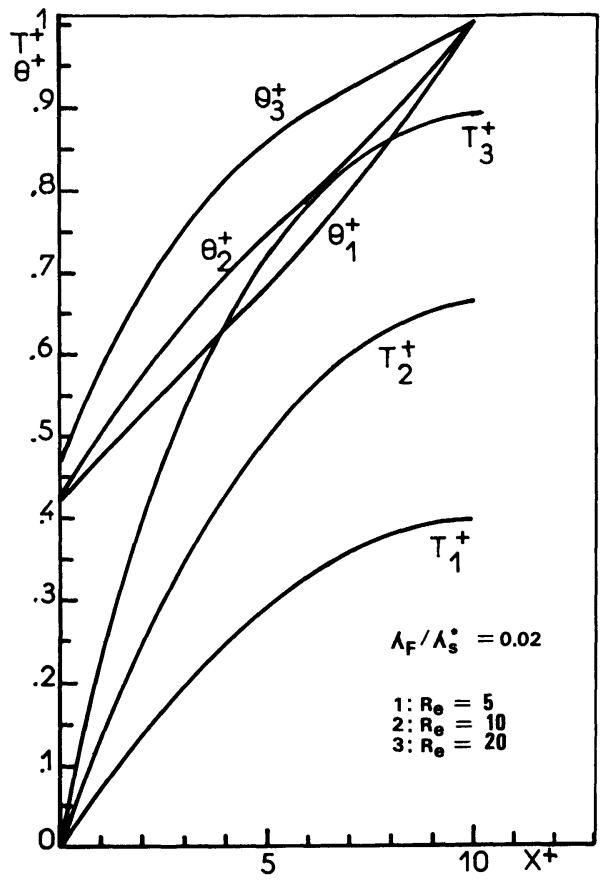

Fig. 3. - Profils des températures $\theta^{+}$et $T^{+}$pour un matériau fini $\left(L^{+}=10\right)$ en fonction de $X^{+}, \lambda_{\mathrm{F}} / \lambda_{\mathrm{S}}^{*}=0,02$ l'indice 1 correspond à $R e=5$; l'indice 2 à $R e=10$; l'indice 3 à $R e=20$. Cas contrecourant.

[Temperatures profiles $\theta^{+}$and $T^{+}$for a finite material $\left(L^{+}=10\right)$ in function of $X^{+}, \lambda_{\mathrm{F}} / \lambda_{\mathrm{S}}^{*}=0,02$; the subscript 1 corresponds to $R e=5$, the subscript 2 to $R e=10$, the subscript 3 to $R e=20$ counter-current case.]

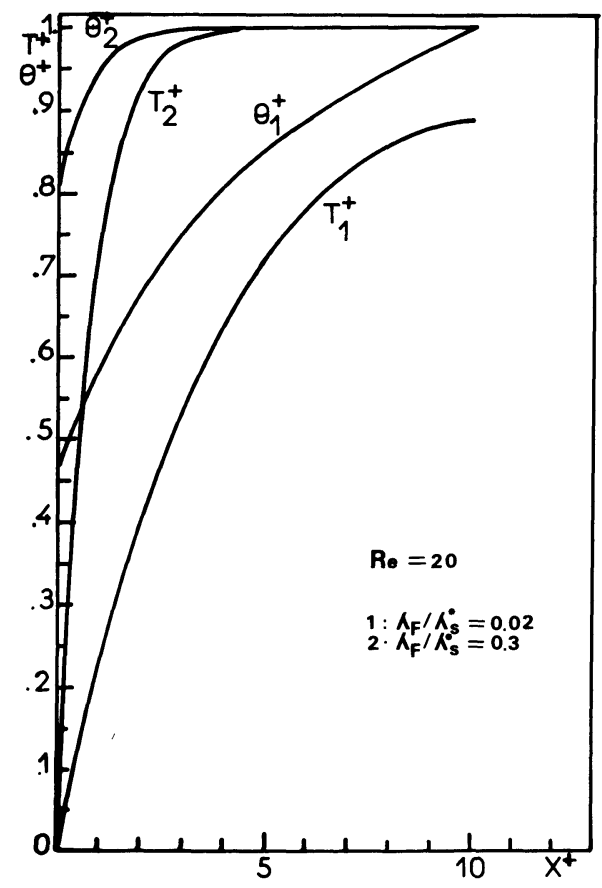

Fig. 4. - Profils des températures $\theta^{+}$et $T^{+}$pour un matériau fin $\left(L^{+}=10\right)$ en fonction de $X^{+}, R e=20$, l'indice 1 correspond à $\lambda_{\mathrm{F}} / \lambda_{\mathrm{S}}^{*}=0,02 ;$ l'indice 2 à $\lambda_{\mathrm{F}} / \lambda_{\mathrm{S}}^{*}=0,3$. Cas contre-courant.

[Temperature profiles $\theta^{+}$and $T^{+}$for a finite material $\left(L^{+}=10\right)$ in function of $X^{+}, R e=20$, the subscript 1 corresponds to $\lambda_{\mathrm{F}} / \lambda_{\mathrm{S}}^{*}=0.02$; the subscript 2 to $\lambda_{\mathrm{F}} / \lambda_{\mathrm{S}}^{*}=0.3$. Counter-current case.]
Figure 5 showns for a given Reynolds number and a given value of $\lambda_{\mathrm{F}} / \lambda_{\mathrm{S}}^{*}$ the profils $T^{+}$and $\theta^{+}$in function of $X^{+}$for materials of different lenghts we note that the gas exit temperature tends towards a maximum limit.

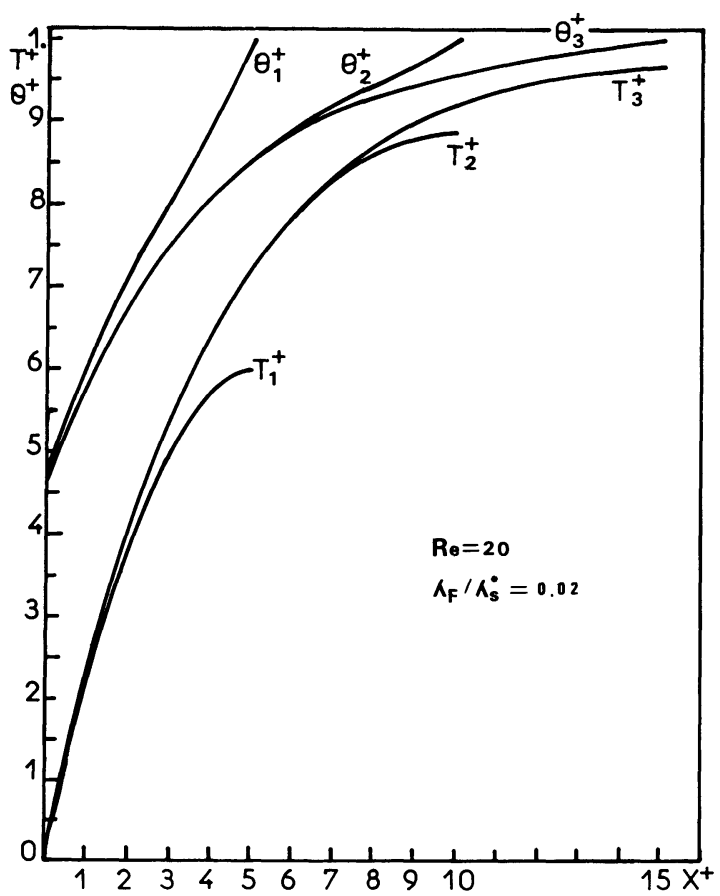

Fig. 5. - Profils des températures $\theta^{+}$et $T^{+}$en fonction de $X^{+}$ pour des matériaux de différentes longueurs $L^{+} ; R e=20$; $\lambda_{\mathrm{F}} / \lambda_{\mathrm{S}}^{*}=0,02 ;$ l'indice 1 correspond à $L^{+}=5$; l'indice 2 à $L^{+}=10$; l'indice 3 à $L^{+}=15$. Cas contre-courant.

[Temperature profiles $\theta^{+}$and $T^{+}$in function of $X^{+}$for materials of different lenghts $L^{+}, R e=20, \lambda_{\mathrm{F}} / \lambda_{\mathrm{S}}^{*}=0.02$; the subscript 1 corresponds to $L^{+}=5$; the subscript 2 to $L^{+}=10$; the subscript 3 to $L^{+}=15$. Counter-current case.]

5. Conclusions. - Such a study allows one to predict the required experimental conditions to bring a gas to a given temperature; to specify the conditions for which heat transfer is optimum; to study the influence of the system parameters (in particular porosity, particle diameter, nature of the material, nature of the gas, ...).

\section{References}

[1] YAGI, S. and Kunil, D., Studies on effective thermal conductivities in packed beds. A.I.Ch.E.J. 3 (1957) 373.

[2] Kun, D., II and SMITH, J. M., Heat transfer characteristics of porous rocks, A.I.Ch.E.J. 6 (1960) 71.

[3] Tsu-Ning TsaO, G., Thermal conductivity of two-phase materials, Ind Eng. Chem. 53 (1961) 5.

[4] Kingery, W. D., Conductivity of multicomponant systems. J. Am. Ceram. Soc. 42 (1959) 12.

[5] CALVET, P., Echanges thermiques dans les lits poreux, I.F.C.E. Journées de la transmission de la chaleur, juin (1961) Paris.

[6] Charet, G., Cours d'analyse numérique Société d'enseignement supérieur, 15005 Paris. 